\title{
OS CAMINHOS PARA A DEMOCRATIZAÇÃO DA EDUCAÇÃO NO BRASIL: QUAL O PAPEL DOS EDUCADORES NESTE PROCESSO?
}

\author{
Clarice Zientarski \\ Sueli Menezes Pereira \\ Universidade Federal de Santa Maria \\ claricezientarski@yahoo.com.br
}

\section{RESUMO:}

O artigo analisa as relações entre os movimentos sociais dos educadores nas décadas de 1970 e 1980 e o processo de democratização da educação, que culminou com a promulgação da Constituição de 1988, referendada pela LDB no 9394/96. Através de uma abordagem qualitativa, buscou-se compreender o papel que os educadores brasileiros desempenharam no ideário que permeou o período de discussões e consolidação da Constituição através de suas reivindicações. As análises textuais se construíram a partir das categorias democracia, políticas públicas, educação e movimentos sociais tendo como aportes teóricos o pensamento de autores como Marx, Gramsci, Ellen Wood, Maria da Glória Gohn e outros, cujos argumentos se fundamentam a partir de uma visão dialética, apoiada na teoria crítica. O trabalho realizado revelou que a democratização da educação se constituía em uma das principais reivindicações dos educadores nas décadas de 1970 e 1980 e as ações presentes em seus movimentos contribuíram, mas não foram definidoras da inserção das noções de democracia que estão postas na Constituição Federal, como por exemplo, a gestão democrática do ensino público.

Palavras-chave: movimentos sociais dos educadores, democratização da educação, Constituição Brasileira de 1988.

\section{THE WAYS OF EDUCATION FOR DEMOCRACY IN BRAZIL: WHAT IS THE ROLE OF EDUCATORS IN THIS CASE?}

\begin{abstract}
:
The article analyzes the relationship between social movements of educators in the 1970s and 1980s and the process of democratization of education, which culminated in the promulgation of the Constitution of 1988, sanctioned by LDB No 9394/96. Through a qualitative approach, aimed to understand because the teachers said to played in the Brazilian ideology that permeated the period of discussion and consolidation of the Constitution through their claims. The textual analysis is built from the categories democracy, public policy, education and social movements and theoretical contributions to the thinking of authors such as Marx, Gramsci, Ellen Wood, Maria da Glória Gohn, and others whose arguments are based from a dialectical view, based on critical theory. The work revealed that the democratization of education is a major demands of teachers in the 1970s and 1980s, and actions in their movements, have helped, but did not define the integration of the concepts of democracy are put in the Federal Constitution, for example, the democratic management of public education.

Key-words: educators of social movements, democratization of education, the Brazilian Constitution of 1988.
\end{abstract}




\section{Introdução}

O presente artigo, fundamentado em pesquisa vinculada ao Grupo de Estudos em Políticas Públicas e Gestão Educacional, da Universidade Federal de Santa Maria, tem como objetivo analisar as relações entre os movimentos sociais dos educadores nas décadas de 1970 e 1980 e o processo de democratização da educação, que culminou com a promulgação da Constituição de 1988, sendo referendado pela Lei de Diretrizes e Bases da Educação (LDB) n ${ }^{\circ}$ 9394/96.

A pesquisa de caráter qualitativo que deu origem a este texto, fundamentou-se em autores que tratam da temática a partir da análise de material escrito (bibliografia utilizada) e oral (depoimentos de sujeitos envolvidos no processo no período em estudo: educadores que foram dirigentes sindicais e educadores de escolas que realizaram movimentos sociais autogestionários). O trabalho teve ainda como um de seus propósitos focalizar questões sobre as práticas desenvolvidas e as relações (regulatórias e emancipatórias) dos profissionais presentes nestes cenários.

Os depoimentos dos sujeitos da pesquisa foram objetos de análise sendo que "os agentes dos movimentos sociais aqui tratados expressam uma insistente preocupação na elaboração das identidades coletivas como forma de exercício de sua autonomia", pois é a partir das "falas que emergem dos movimentos que muitos autores assumiram o termo (movimento social) e procuraram elaborá-lo teoricamente" (SADER, 1995.p.50-51).

Isto significa que os educadores que foram ouvidos na amostragem são sujeitos históricos que participaram dos movimentos, na condição de grevistas e/ou dirigentes sindicais ou, então, como protagonistas no processo de articulação ou desenvolvimento de experiências sociais autogestionárias, entendendo que "é o homem como sujeito histórico real, que no processo social de produção e reprodução cria a base e a superestrutura, forma a realidade social como totalidade de relações sociais, de instituições e idéias" (KOSIK, 1985, p.51).

Todos os educadores que participaram da pesquisa, na condição de sujeitos, de agentes, são gaúchos e participaram destes movimentos no Estado do Rio Grande do Sul. Salienta-se que, neste momento, "ao longo dos anos 80, os professores brasileiros em quase todo o país seguiram um percurso semelhante, pois as reivindicações eram semelhantes" (BULHÕES \& ABREU, 1992, p. 11).

A seleção dos sujeitos constituiu-se de uma amostra heterogênea com professores de ambos os sexos, de diferentes municípios, que atuam ou atuaram na Educação Básica. Através desta amostra buscou-se saber, a partir do relato dos professores sobre a sua vivência nos movimentos, as relações que se estabeleceram entre esta experiência e o processo de democratização da educação.

A proposta se justifica pela grande incidência dos movimentos sociais no período em estudo, pelos movimentos realizados pelos educadores com implicações diretas na sociedade e pelo caráter de descentralização proposto pela legislação que visa à integração da educação com a dinâmica de organização mais ampla da sociedade. Considerando que o tema da democratização constituiu-se em uma das reivindicações dos educadores no sentido de fazer com que a educação cumprisse seu papel político e social, Nosella (2005), afirma que:

(...) durante os anos oitenta o pensamento pedagógico se modernizou, se arejou ao assumir sua dimensão de engajamento político (...). Mais ainda: politicamente, a maioria dos educadores dos anos oitenta, sabedora de

Revista HISTEDBR On-line, Campinas, n.34, p.154-166, jun.2009 - ISSN: 1676-2584 155 
que a escola não se explica por ela própria e sim pela relação política que mantém com a sociedade, lutou para colocar na administração educacional, partidos e homens compromissados com os objetivos da escola popular e libertadora (NOSELLA, 2005, p.223-238).

Com este propósito, na luta por direitos sociais, defendendo a proposta de democratização da educação, os educadores, através de fóruns, debates, greves, discussões, manifestações públicas, assembléias da categoria e mobilizações organizadas com ou sem o seu sindicato constituíram movimentos sociais de grande porte e de grande repercussão na sociedade.

Ao longo dos anos 1980, portanto, os educadores brasileiros desempenharam um papel relevante na luta pela mudança da situação educacional do país. O magistério participou intensamente deste processo, realizando neste período, um difícil aprendizado de democracia, principalmente em sua relação com o Governo e nas relações internas de seu movimento. Neste momento, os professores viveram, junto à classe trabalhadora brasileira, a expectativa de uma constituinte livre e soberana, o movimento das "diretas já" e, movidos pela esperança de melhorar suas condições de vida, de realizar movimentos autônomos de modo que os sujeitos envolvidos fossem capazes de "durante as lutas constituírem-se como classe (THOMPSON, 1979, p.232.)".

Gohn (1992) indica que os movimentos sociais populares dos anos 1970 e 1980, representaram formas renovadas de educação popular, pois eles não ocorreram através de um programa previamente organizado, mas, através de princípios que fundamentaram programas deste tipo de movimento formulados por agentes institucionais determinados, tais como grupos de assessorias articulados às igrejas, aos partidos políticos, às universidades, às instituições governamentais nacionais e internacionais, aos sindicatos, etc...

As ações realizadas pelos grupos envolvidos em movimentos sociais culminaram com a aprovação no Congresso Nacional da Nova Lei de Diretrizes e Bases da Educação Nacional - Lei n ${ }^{\circ} 9.394$ de 20/12/1996. Esta Lei, que é fruto das discussões, análises, lutas de interesses e de engajamento de setores da sociedade, após décadas de impossibilidade de exercer esta prática, por cerceamento da liberdade de manifestação decorrente dos mecanismos ditatoriais instaurados no Brasil nos anos 1960 - 1980, não atendeu todos os propósitos que os educadores buscavam, mas de uma ou outra forma, permitiu que, num anseio de participação, a comunidade educativa experimentasse uma prática democrática.

$\mathrm{O}$ que se constatou, foi que o movimento crítico e reivindicatório que buscava mudanças no sistema educacional, não conseguiu atingir seus intentos, sendo que a lei LDB 9394/96 - sancionada serviu, em grande parte, aos interesses do poder dominante, omitindo as responsabilidades cabíveis ao Estado, permitindo, assim, que o "Executivo colocasse em andamento seu próprio projeto político-educativo por outras vias" (SHIROMA, et al 2002, p.51). Isto se explica em parte, porque, tais mudanças, decorrentes do processo de descentralização das funções do Estado, proporcionalmente, acabam por repassar um maior compromisso à sociedade e, em especial à comunidade escolar.

Neste sentido, é importante entender que o governo, ao lançar "mão do ardil" de incorporar, na legislação, algumas bandeiras do movimento dos educadores, consolidadas nos anos de 1980, "ceifou-lhes a fecundidade, adulterou o sentido original de seu conteúdo" (SHIROMA, et al 2002, p.52), ficando, portanto, na sociedade o senso comum, a idéia de que foi ela, através dos seus movimentos a responsável pelas mudanças advindas da aprovação da LDB. Isto, porque o Estado, empenhado em garantir a reprodução da sociedade capitalista desenvolve estratégias de auto-legitimação mediante discurso e prática das políticas públicas e das ações populares. Produz-se, a partir disso, "uma 
linguagem artificial e sedutora com o objetivo de envolver os agentes sociais em uma lógica e em uma dinâmica de responsabilidades na realização de tarefas concebidas por tecnocratas à distância", impondo à sociedade a tarefa de resolver seus próprios problemas, realizando ações que caberiam ao Estado (SHIROMA, et al 2002, p.52).

Embora não sendo o objetivo deste texto entender como se constrói esta concordância, ou porque o senso comum se instala na forma de ver este processo, esta análise permeia a discussão, ao trazer fatos e momentos em que se estabelece este consenso e, como contraponto, as ações desencadeadas pelos movimentos sociais dos educadores. Apresenta o sentido de democracia e descentralização em uma sociedade capitalista, pois, as políticas públicas, principalmente as de caráter democratizante são mediatizadas pelas lutas, por conflitos e pressões entre elas. Por serem dinâmicas e concretas elas são estrategicamente empregadas e acabam sendo tomadas (pelo Estado),como se fosse também seu interesse, no andamento dos movimentos sociais, expressando a habilidade do governo em implantar ações que atendem aos seus interesses e os dos grupos aos quais serve, o que leva ao entendimento de que os movimentos realizados pelos trabalhadores de várias categorias profissionais, pelos intelectuais, por setores da Igreja, pela sociedade civil durante os anos de 1970 e 1980, foram importantes, porém, não definidores dos rumos da educação brasileira.

Com esta perspectiva o trabalho trata inicialmente da acepção de democracia. No segundo momento, trata dos movimentos realizados pelos educadores no período em estudo, que servirão como um fio condutor de análises e como uma fonte necessária para contextualizar o momento vivido. Por fim, pretende analisar dialeticamente as relações entre os movimentos sociais realizados pelos educadores, as conquistas presentes na Legislação e as dificuldades para a implantação de ações que beneficiam a sociedade.

\section{Democracia: entre o real e o ideal}

Embora o termo não seja novo, a palavra democracia assumiu um lugar central no campo político durante o século XX, podendo ser entendida de várias formas, sendo uma delas, a idéia de soberania popular, ou pelo que significa o próprio nome "o governo do povo ou pelo poder do povo", ou por significar "a reversão do governo de classe", em que o homem comum, desafia a dominação dos ricos (WOOD, 2002, p.7). Neste sentido entende-se com Benevides (2001) que "a democracia significa o desafio ao governo de classe". A democracia também pode ser percebida como o "regime político da soberania popular", com respeito integral aos direitos humanos (BENEVIDES, 2001, p.21).

De qualquer forma, ao se analisar a questão da democracia, tanto na interpretação de Wood, quanto de Benevides, a democracia é conflitante no sistema capitalista. Os princípios expressos nas abordagens das autoras evidenciam que apesar da importância crítica da luta em favor de qualquer reforma democrática no âmbito da sociedade capitalista, o capitalismo se contrapõe à democracia, não só pela clareza de que o capitalismo representa o governo de classe pelo capital, mas também no sentido de que o capitalismo limita o poder do povo.

Para Gramsci, o primeiro elemento da sustentação da política e de qualquer ação coletiva "é que existem, verdadeiramente, governantes e governados, dirigentes e dirigidos. Toda ciência e a arte política se baseia neste fato primordial e irredutível”. (...) Quando discute o mito do Príncipe a que Maquiavel dá uma concepção e forma fantástica e artística, ele reafirma esta posição, pois que esta seria a forma "pela qual o elemento doutrinário e racional se personifica num Condottiere" que representa plástica e 
antropomorficamente "o símbolo da vontade coletiva para um determinado fim político, a concretização da civilização moderna (GRAMSCI, 1978, p. 46)".

Isto coloca em evidência o sentido que o capitalismo assume como modo de produção e organização da sociedade, visto que não existe capitalismo no qual a vontade do povo prevaleça sobre os imperativos do lucro e da acumulação; não existe capitalismo em que as exigências de maximização dos lucros não definam as condições básicas de vida. Portanto, o capitalismo é incompatível com a democracia (WOOD, 2002, p.7.; BENEVIDES, 2001.p.21).

A pesquisadora Ângela Martins (2002, p. 12) considera que para o bom funcionamento da democracia, não basta que grande número de cidadãos participe, direta ou indiretamente, da tomada de decisões coletivas. Não basta também, a existência de regras de procedimento como a da maioria, isto é, da unanimidade. Torna-se "indispensável uma terceira condição: é preciso que aqueles que são chamados a decidir ou a eleger os que deverão decidir sejam colocados diante das alternativas reais e postos em condição de poder escolher entre uma e outra". Isto implica em assegurar àqueles que irão decidir a liberdade de opinião, de expressão de suas idéias, de reunião, de associação e o respeito às decisões que resultam do processo democrático.

Em relação à democracia, a concepção e a prática política a nós legadas, foram fruto das forças materiais e culturais então existentes, evidenciando que qualquer entendimento sobre democracia passa necessariamente pela condição de existência de uma sociedade concreta, o que leva ao indicativo de que na sociedade capitalista, a democracia é "frágil, exatamente porque supõe a expressão das condições concretas, contraditórias da vida social, dos interesses de grupos e classes sociais" (CIAVATTA, 2003.p.90).

Diante do exposto, pode-se considerar que democracia implica em participação direta e esta participação se consegue praticando, exercitando, o que consiste na possibilidade de aquisição de uma consciência política. Em relação ao Brasil, parece claro que o conjunto da sociedade precisaria aprender a exercer o poder, exercendo o poder e, neste caso, construindo a participação na tomada de decisões. Rosa Luxemburgo ao discursar no Primeiro Congresso Nacional dos Conselhos Operários em Berlim afirmou: "Não há nenhum outro meio de lhes ensinar isso" (...) As massas são educadas quando passam à ação (Luxemburgo, 1919, apud LOUREIRO, 1999, p.39), indicando que o processo de aprendizagem da democracia se dá pela prática da participação e da tomada de decisões.

Com respeito à educação, portanto, democratização da educação pressupõe a democratização do conhecimento; a democratização do acesso, a garantia de permanência; e a democratização da gestão. Este conjunto de idéias foi e continua sendo bandeira levantada pelos educadores ao longo dos tempos. Estas mesmas reivindicações chegaram a ser formalizadas na Lei, porém, se a Lei não garante a eqüidade dos direitos, o poder aumenta os privilégios de poucos e a cidadania é enfraquecida, pois não são aplicados nem ampliados os direitos em todas as formas que eles poderiam assumir. A democracia também se torna fictícia, passando a existir como promessa e não como mecanismo transformador.

Por esta razão os educadores insistiam para que a democratização se tornasse uma realidade, merecendo destaque em suas reivindicações a questão da gestão democrática na educação, pela compreensão de que ela possibilitaria à comunidade educativa um papel decisivo em relação aos assuntos educacionais. É evidente que a gestão democrática por si só não garante o pleno funcionamento da educação, considerando seus limites e possibilidades. Todavia é o caminho mais curto para minimizar as dificuldades históricas 
das escolas da rede pública e de valorizar os movimentos realizados pelos educadores que defendiam este fim.

Nesta perspectiva, buscando conquistarem direitos como: participação, democratização, valorização do trabalho, capacitação profissional e autonomia da escola os educadores se organizaram para provocar mudanças educacionais e sociais no Brasil nas décadas de 1970 e 1980, especialmente durante o processo de gestação da Constituição Federal e da LDB.

\section{Os movimentos dos educadores brasileiros nas décadas de 1970 e 1980}

No Brasil, apesar do processo de democratização da sociedade estar se revelando lento e difícil de ser conquistado, pois a própria comunidade não tem participado de forma sistemática deste movimento, na educação isto não é diferente; foi a ação das forças na sociedade civil que provocou, em parte, os pequenos avanços conquistados. Neste sentido, pode-se identificar ao longo da história brasileira muitos movimentos gerados na sociedade civil, que exigiam (e exigem) a ampliação do direito à educação à parcelas cada vez mais amplas da sociedade e o direito à democracia efetiva.

A luta dos professores brasileiros acompanhou, em linhas gerais, a trajetória do movimento sindical, participando de movimentos e campanhas. Devido às características específicas da conjuntura brasileira, a partir da década de 1960, a maior parte dos programas de educação popular se desenvolvia através de campanhas de alcance regional e nacional, a partir do Estado, da Igreja ou de entidades representativas de nível nacional.

O movimento de Educação de Base, que foi criado por um convênio entre a Conferência Nacional de Bispos do Brasil e o Governo Federal em 1961, tinha como objetivo o trabalho de educação de base junto a camponeses do Norte, Nordeste e CentroOeste. O Movimento de Cultura Popular e os Centros Populares de Cultura foram programas que surgiram no final da década de 1960 por iniciativa de grupos universitários, de educadores, intelectuais e de artistas que difundiam o teatro e o cinema político para as classes trabalhadoras em diversas partes do Brasil.

A política educacional desta fase mostra a disputa de interesses contraditórios e isto pode ser constatado à medida que os interesses pelas questões educacionais se reduzem à luta em torno da lei de Diretrizes e Bases da Educação Nacional e à Campanha da Escola Pública. A polarização de interesses evidenciava de um lado os setores populares representados até certo ponto pelo Estado e por alguns intelectuais de classe média e, de outro, por um grupo heterogêneo do qual fazia parte a burguesia nacional, o capital estrangeiro monopolista e os representantes das antigas oligarquias. Buscava-se com isto a inserção do país na nova ordem econômica alicerçada no desenvolvimento de algumas nações periféricas, aproveitando as riquezas e a mão-de-obra barata.

Esta realidade, conforme Severino (1986), sofre alterações com a política implementada pelo governo ditatorial pós-64, considerando seu caráter puramente mercantil que tinha uma função ideológica muito atuante, respondendo à reprodução da ideologia e, através dela, do sistema de relações sociais. O que se queria "do sistema educacional é a produtividade, o baixo custo de mão-de-obra numerosa, mas com qualificação puramente técnica, disciplinada e dócil, adequada às necessidades da manutenção do sistema econômico vigente". Esta política acaba criando na prática, dois sistemas: o público e o privado (SEVERINO, 1986, p.92). O autor afirma que com o privatismo empresarial, a educação para atender os interesses capitalistas, tornou-se elemento da indústria cultural, servindo para a comercialização de produtos culturais e 
bens simbólicos a baixo custo e com muita rentabilidade, buscando a extensão do mercado neoliberal que começava a se afirmar para permanecer.

O período ditatorial se pautou em termos educacionais pela repressão, privatização de ensino, exclusão de boa parcela dos setores mais pobres do ensino de boa qualidade, institucionalização do ensino profissionalizante, divulgação de uma pedagogia mais calcada em técnicas do que na ciência, tentativas variadas de desmobilização do magistério através de "abundante e não rara e confusa legislação educacional" (GHIRARDELLI, 2003, p.126). Um exemplo do que foi afirmado pôde ser visto ainda, entre junho de 1964 e janeiro de 1968, quando foram firmados doze acordos entre o Ministério da Educação e Cultura e a Agency for International Development ("os acordos MEC-Usaid"), o que comprometeu a política educacional brasileira às determinações de um grupo específico de técnicos norte-americanos, ao colocar em prática a necessidade de submeter as diretrizes da escola ao mercado de trabalho.

A repressão desencadeada no país pelo poder militar queria fazer calar os movimentos populares em defesa da democracia, da liberdade e do direito à educação, porém, assim como as classes dominantes do país se organizaram no sentido de combater os movimentos populares, muitos líderes comunitários, educadores, estudantes, religiosos e outros componentes da sociedade civil, comprometidos com a educação e engajados na luta pela democratização, se organizaram contra os movimentos da classe dominante, o que lhes ocasionou perseguições, torturas, cassações e exílios.

Os efeitos destes movimentos foram sentidos já no início dos anos 1970, quando pequenas organizações anteriormente identificadas com o espírito assistencialista dos programas da Aliança para o Progresso abandonam esta estratégia e incorporam, tanto o método Paulo Freire de "educação popular", quanto o "princípio de que só a participação direta do povo seria capaz de conduzir o país ao desenvolvimento" (DOIMO, 1995, p.76). Freire (1981) afirma que as massas descobrem na educação um canal para um novo status e começam a exigir mais escolas. "Começam a ter uma apetência que não tinham. Existe uma correspondência entre as manifestações das massas e a reivindicação". É o que chamamos educação das massas (FREIRE, a.1981, p.37).

Brandão (1986) esclarece que a Educação Popular surgiu na década de 1960 "no pequeno domínio de teorias e trabalhos que pensamos haver inventado entre 1960 e 1964 e a que mais tarde, nos anos de 1970 e 1980 (...), surgiu e por algum tempo floresceu um tipo relativamente inovador de prática pedagógica" (BRANDÃO, 1986, p.15). O mesmo ponto de vista é destacado em Wanderley (1984) quando avalia as ações do MEB (Movimento de Educação de Base).

O MEB “desenvolveu uma original pedagogia popular, engendrando subsídios concretos para uma efetiva integração da teoria com a prática, para a investigação militante, para a educação libertadora" (WANDERLEY p.16). A idéia é reafirmada por Paludo (2001, p. 90) quando diz: "é nos anos 1960, com Paulo Freire, que no Brasil se tem, pela primeira vez, de forma consistente, uma pedagogia anunciada das classes populares". Conforme a autora, estava emergindo aí uma teoria da educação brasileira que parte da realidade local e busca a transformação da sociedade, na qual as classes populares são agentes centrais. Portanto, desde meados das décadas de 1970, o movimento que havia iniciado na década de 1960, crescia e reivindicava mudanças no Sistema Educacional.

Coutinho (2003), ao examinar o processo de democratização no período brasileiro pós 70, afirma que se entendemos democracia como um processo, como socialização crescente da política no rumo da socialização do poder, como uma conquista efetiva não só de regras do jogo, mas, também de igualdade substantiva, é preciso dizer com clareza que 
essa democracia é claramente incompatível com o modelo político, econômico e social implantado no país (COUTINHO, 2003, p.31-32).

A partir de 1979, quando foi concedida a anistia política, os líderes dos movimentos que haviam sido banidos do país desde o início do regime de força, em 1964, tiveram permissão para retornar e os que aqui estavam puderam começar a dura luta pela reivindicação de direitos perdidos. Diante desta situação muitas vão ser as manifestações sociais populares. Durante este processo, de lutas pela redemocratização, com relação à educação, foi criada a Associação Nacional de Educação (Ande) em 1979, entidade não corporativa que se reclamava herdeira da luta dos educadores progressistas em prol do ensino público, gratuito, obrigatório, universal, laico e de boa qualidade. Em Campinas surgiu o Centro de Estudos Educação \& Sociedade (Cedes), cujo nome mostrava o clima dos educadores da época.

A Ande o Cedes e a Associação Nacional de Pós-Graduação em Educação (ANPED) passaram a organizar as Conferências Brasileiras de Educação. Neste contexto, as políticas educacionais assumiram centralidade mediante as novas proposições da esfera governamental, dos movimentos sociais e sindicais e das organizações acadêmicas como a ANPED (Associação Nacional de Pesquisa e Pós-Graduação em Educação), ANPAE (Associação Nacional de Política e Administração da Educação), ANFOPE (Associação Nacional de Formação dos Profissionais da Educação), dentre outras. Retomou-se a partir deste momento, um espaço de crescente fluxo de idéias na área educacional.

$\mathrm{Na}$ memória (oral e também nos registros), a partir de pesquisa junto aos educadores gaúchos sindicalizados (CPERS), sujeitos da pesquisa, surgem os indicativos de que no período em estudo os professores brasileiros desempenharam um papel muito importante na luta pela mudança da situação educacional do país. Isto se comprova com as falas dos professores:

A partir da década de 1980, o magistério intensificou sua luta, voltandose não apenas para reivindicações salariais, organizando-se em função dos acordos que não eram cumpridos pelos governantes, perdas de direitos adquiridos, luta pela democratização da escola pública... (depoimento de um professor)

O magistério participou intensamente deste processo realizando um aprendizado da democracia, principalmente em sua relação com o Governo e nas relações internas de seu movimento. No campo educacional, as políticas foram variando, bem como o avanço da industrialização e das tecnologias. Iniciou-se um processo de introdução da tecnologia educacional na profissionalização e formação dos educadores, o que ocasionou novos debates em torno da formação, a partir da crítica das concepções sobre o tema.

Um grande número de educadores engajados no movimento pela escola pública de qualidade, como pessoas que refletem sobre a realidade social e sua própria prática, determinada por uma sobrecarga de trabalho e por um aviltante salário, continuou com seus movimentos, embora esta não fosse a realidade de todo o professorado brasileiro, como informam os próprios professores.

A maior parte dos colegas que se envolveram nos movimentos que realizamos nas décadas de 70 e 80 , demonstravam vontade de lutar, de provocar uma verdadeira revolução social, estavam imbuídos de um papel social e político e acreditavam nisto (...), infelizmente alguns professores esperavam que os outros, lutassem por eles (...), pior que isto, foi constatar que alguns professores acabaram incorporando o discurso do Governo, conformaram-se com a situação e passaram a 
defender as propostas apresentadas por intelectuais ligados ao Governo (depoimento de um professor).

Neste sentido cabe destacar que a trajetória do movimento teve três momentos principais (BULHÕES \& ABREU, 1992). No primeiro momento, entre 1979 e 1980, a categoria intensificou a mobilização, aprendendo que a valorização profissional depende de sua luta, rompendo com a idéia do Magistério como sacerdócio. No segundo momento, tentou garantir um parâmetro definitivo para a situação salarial de modo que a luta por salários não precisasse ser constantemente retomada. No terceiro momento, o Magistério, que participava efetivamente dos movimentos, aprendeu que sua luta por melhores salários e pela qualidade da escola pública precisa ser permanente.

Com este entendimento, os professores começaram a reconhecer a necessidade de saber articular mobilização com negociação, pois não haveria "a última greve" nem a conquista de parâmetro definitivo (BULHÕES \& ABREU, op.cit. p. 17-18). Entre as reivindicações, os professores incluíram os itens relativos à questão educacional que havia surgido em seus debates em 1979 e 1980, como, por exemplo, a eleição de diretores, a aplicação de recursos na educação, a democratização ao acesso e a permanência na escola.

O magistério começou então a fazer um aprendizado no sentido de articular mobilização com negociação e, com isto, aproxima-se da prática sindical do conjunto dos trabalhadores do setor privado que, além dos reajustes determinados pela política salarial, negocia uma vez por ano, em sua data-base, uma pauta de reivindicações que inclui, também, o reajuste salarial. Foi o momento em que os educadores aprenderam com os demais trabalhadores a importância da sindicalização da luta do magistério e passaram, então, a ser considerados trabalhadores em educação, filiando-se à Central Única dos Trabalhadores.

De acordo com um dos sujeitos da pesquisa:

Este momento foi muito importante. Mesmo que na própria categoria tivessem ocorrido alguns desentendimentos, pois alguns colegas não queriam ser considerados "trabalhadores" e sim "educadores", foi uma tomada de decisão madura. Penso que nós educadores ainda não tínhamos o entendimento do que significava o trabalho como categoria (...) compreendemos que precisávamos do apoio de outras categorias profissionais e elas também precisavam do nosso apoio. (depoimento de um professor)

Ao mesmo tempo iniciava-se um debate mais amplo e sistemático da questão Educacional. A luta pelo cumprimento dos acordos de greve levou os professores a reivindicações e mobilizações constantes. A política econômica regressiva respondia à necessidade de pagar a dívida externa brasileira seguindo as determinações do FMI. Para implementar esta política, o Governo procurou conter o avanço do movimento sindical e da luta democrática no país. Um dos exemplos disto foi a intervenção no Sindicato dos Metalúrgicos de São Bernardo do Campo, já na greve de 1980, sinalizando a intenção de conter o avanço dos sindicatos. Estas situações também repercutiram nos movimentos dos educadores: ameaças, cortes de ponto, proibição de greves, punição de grevistas, entre outros.

Apesar destas tensões ocorridas durante o período em estudo, havia a sinalização para a abertura política e para o processo constituinte, o que culminou com a aprovação da Constituição Federal de 1988 e, com ela o encaminhamento para a reforma educacional. Este indicativo fez com que a sociedade civil e especialmente os movimentos sociais 
populares, incluindo-se o movimento dos educadores, acreditasse que os tempos "ruins" e repressivos estavam acabando, no entanto, o que se observou à medida que se encaminhava a votação da Lei, que deveria atender aos anseios da sociedade, foi o contrário. Para isto, o Governo contou com intelectuais denominados por Shiroma (et al 2002, p. 52) de "arautos da reforma" para, de forma sutil e matreira, anunciar as alterações que respondiam aos interesses do capital internacional e, com isto, a dependência dos organismos internacionais, passando à Sociedade e aos educadores que se envolveram em movimentos sociais a idéia de que suas reivindicações foram atendidas.

O Governo ao tomar para si e incorporar na legislação reivindicações dos movimentos dos educadores consolidadas nos anos de 1980, "ceifou-lhes a fecundidade e, adulterou o sentido original de seu conteúdo" (SHIROMA, et al. 2002, p.52). Contou nesta campanha, como afirmam as autoras, com "renomados intelectuais de participação na construção de propostas dos educadores na década anterior". Muitos educadores envolvidos nos movimentos "custaram a perceber a manobra", como assegura uma educadora em seu depoimento: "nós queríamos acreditar que as nossas reivindicações estavam sendo atendidas e vibramos com o desenrolar dos fatos", o que evidencia que o momento histórico vivido era de "otimismo, de esperança" (Testemunho de uma professora) .

Desta forma se consolida a implantação da Constituição Federal de 1988 e reiterase na Lei de Diretrizes e Bases da Educação Nacional aprovada em 1996 o consenso de que o processo foi democrático e atendeu aos interesses mais amplos da sociedade brasileira sem que os interesses do capital fossem questionados.

\section{Considerações}

Os educadores brasileiros participaram nas décadas de 1970 e 1980 de movimentos sociais de caráter contestatório e reivindicatório. Durante as lutas os educadores envolveram-se e trataram de questões que diziam respeito ao momento vivido, à democratização da gestão e à qualidade da escola pública. Neste período no Brasil viveu-se o movimento das "diretas já", o movimento Pró-Constituinte e movimentos sociais que buscavam mudanças na área educacional, como, por exemplo, o Fórum Nacional em Defesa da Escola Pública que surgiu em "1986 em função de articulações realizadas objetivando a elaboração de uma Carta Magna para o País” (GOHN, 1997, p.78).

O Fórum agiu em defesa da educação e foi organizado para atuar na Constituinte, tendo papel decisivo na construção do projeto da LDB (PL n $\left.{ }^{\circ} 1.258 / 88\right)$, o qual, embora representativo da sociedade brasileira, foi substituído por outro no Senado, sendo este elaborado à revelia da sociedade e aprovado no Congresso Nacional, colocando a lei em vigor com as características definidas nesta alteração.

Neste contexto, embora muitos não "entendessem o que estava acontecendo" (depoimento de uma professora), lideranças do magistério passaram a participar de forma crescente da vida política do país, na medida em que, para a defesa dos interesses da categoria, precisavam enfrentar problemas que afligiam o restante da sociedade, o que não significou que "o magistério tenha se partidarizado" (BULHÕES \& ABREU, 1992, p.41), considerando as ações partidárias como representantes da adoção de concepções de mundo diversas da forma assumida pela luta da categoria.

O Governo em vários Estados brasileiros, durante as décadas de 1970 e 1980 reprimiu os movimentos dos educadores chegando a ameaçar a intervenção nos sindicatos, estabelecendo um diálogo difícil e resistindo às propostas reivindicatórias, revelando a intenção de conter o avanço da luta pela democratização da educação. 
Em 1989 o país viveu um dos pontos mais altos da luta pela democracia: as primeiras eleições diretas para Presidente da República. Neste processo, a participação popular foi intensa na expectativa de redemocratização do país. Este momento se caracterizou pela participação, como afirma um dos sujeitos desta pesquisa: "participamos junto com as demais categorias, de um movimento social mais amplo que foi o encaminhamento da democratização do País, mas não esperávamos que alguém como o Collor vencesse as eleições". Pode-se afirmar, portanto, que as lutas dos educadores brasileiros resultaram do quadro mais amplo vivido pela educação nacional e pelos trabalhadores como um todo.

É interessante observar, no entanto, a contradição entre o que buscavam os movimentos sociais em relação a um governo democrático, eleito pelo povo e a candidatura de Collor de Mello, como um rearranjo político dos setores dominantes. A vitória eleitoral de Fernando Collor em 1989 representou a vitória dos grupos dominantes e a desmobilização dos segmentos populares. Ao atender à cartilha do Consenso de Washington, Collor, no exercício de seu governo (1990/92), deu início ao desmonte do aparelho de Estado. O referido documento indicava, dentre outras recomendações, a privatização de empresas estatais, a abertura do mercado interno, o controle da inflação, uma moeda forte, os cortes nas políticas sociais e a flexibilização das leis trabalhistas, portanto, enquanto o embate político pela implementação de uma constituição democrática se desenrolava, o processo de reestruturação do capitalismo mundial, dentre outros componentes, apontavam para a afirmação do neoliberalismo no Brasil.

Em se tratando de perspectiva educativa constata-se que as reivindicações do magistério, que vêm se arrastando ao longo dos tempos, não obtiveram por parte do Estado ações efetivas para seu atendimento. O governo brasileiro formulou e ainda formula políticas a fim de satisfazer às exigências dos organismos internacionais, tendo nas diretrizes a forma de assegurar à população o direito à educação, colaborando com o esforço mundial em favor da universalização da educação básica (DAVIES, 1999), indicando políticas voltadas para a quantidade, mas sem comprometimento com uma educação de qualidade. Este fato não deixa dúvidas quanto ao interesse do Estado em adotar políticas educacionais que poderiam oferecer condições à população, especialmente as classes populares, no sentido de superar a situação social a que tem sido submetida, mas não o faz, evidenciando que os interesses sociais não são prioritários nas políticas de Estado.

O que se percebe com Souza (2005) é que a influência dos órgãos internacionais, como o Banco Mundial que até os anos 70, intervinha, mas, se limitava a ser um órgão técnico e financiador de projetos específicos, a partir dos anos 80, passou a intervir nas políticas públicas e sociais, o que implicou em uma atuação muito mais determinista no processo de ajuste estrutural imposto aos países membros aos quais empresta dinheiro, base para implementar a globalização e discutir o papel dos movimentos sociais neste processo de mudanças sociais (SOUZA, 2005). Desta forma os organismos internacionais, como o Fundo Monetário Internacional (FMI), o Banco Mundial, o Banco Interamericano de Desenvolvimento (BID) e o Programa das Nações Unidas para o Desenvolvimento (PNUD) vão desempenhar o papel de conduzir as reformas dos Estados nacionais, sobretudo nos países do capitalismo periférico e semi-periférico (ARRIGHI apud CIAVATTA e FRIGOTTO, 2003, p.3).

Esta prática contrapõe-se ao que os movimentos e, em especial o movimento dos educadores, têm defendido como essencial na educação para a cidadania, que é a educação e a formação humana, a democratização ao acesso e permanência, a democratização da gestão, a formação e a valorização profissional, dentre outras reivindicações. Para que as 
reivindicações dos educadores e a sociedade como um todo, deixassem de ser reclamações e se tornassem realidade, deveria haver um grande salto do direito formal para o direito efetivo, pois a pior de todas as ilusões é a de que a democracia se dá de maneira natural. Ao contrário, os direitos humanos e sociais precisam ser construídos e/ou conquistados e isto demanda luta, organização e estabelecimento de prioridades. Na relação desses direitos, seria listado como prioridade o direito à educação, o direito à participação na tomada de decisões, à democracia e à autonomia.

\section{Referências}

BENEVIDES, Maria Vitória. "Democracia de iguais, mas diferentes". In BORBA, A. FARIA N. \& GODINHO, T. (Orgs.) Mulher e Política: Gênero e Feminismo no PT. São Paulo: Perseu Abramo, 2001.

BRANDÃO, Carlos Rodrigues. Educação Popular. São Paulo: Brasiliense, $3^{\text {a }}$ ed. 1986.

BULHÕES, Maria da Graça, ABREU, Mariza. In. A Luta dos professores Gaúchos1979/1991. O difícil aprendizado da democracia. Porto Alegre: L\&PM. 1992

CHEVALIER, Jean-Jacques. As grandes obras políticas: de Maquiavel aos nossos dias. Rio de Janeiro: Agir $2^{\mathrm{a}}$ ed. 1982.

CIAVATTA M. e FRIGOTTO, Gaudêncio. Educação básica no Brasil na década de 1990, subordinação ativa e consentida à lógica do mercado, Educação e Sociedade, Campinas: Vol. 24, no 82, p.93-130, 2003. http://www..cedes.unicamp.br Acesso, 05/03/2009, $13 \mathrm{~h}$.

COUTINHO, Carlos Nelson. A dualidade dos poderes. Introdução à teoria marxista do Estado e da revolução. São Paulo: Brasiliense, $2^{a}$ ed. 2003.

DAVIES, Nicholas. O FUNDEF e o orçamento da educação: desvendando a caixa preta. Campinas, São Paulo: Autores Associados, $2^{a}$ ed. 1999.

DOIMO, Ana Maria. A Vez e a Voz do Popular - Movimentos sociais e participação política no Brasil Pós-70. R.J: Relume -Dumará: ANPOCS 1995.

FREIRE, Paulo, Educação e Mudança. Rio de Janeiro: Paz e Terra, 1981. V.1.a.

.Pedagogia do Oprimido. Rio de Janeiro: Paz e Terra. $2^{\text {a }}$ ed.1981.

GHIRALDELLI Jr., Paulo. Filosofia e História da Educação Brasileira. São Paulo: Manole, 2003.

GOHN, Maria da Glória. Movimentos sociais e educação. São Paulo: Cortez, 1992.

História dos Movimentos e lutas Sociais A construção da cidadania dos Brasileiros. São Paulo: ed. Loyola, 1997.

GRAMSCI, Antônio. Concepção dialética da história. Rio de Janeiro: Civilização Brasileira. 1978.

KOSIK, Karel. Dialética do Concreto. Rio de Janeiro: Paz e Terra, $3^{\text {a }}$ ed. 1985.

LOUREIRO, I. Maria. Rosa Luxemburgo - vida e Obra - São Paulo: Expressão Popular 1999. $1^{\mathrm{a}} \mathrm{ed}$.

MARTINS, Ângela M. A Autonomia da escola: A (ex) tensão do tema nas políticas públicas. São Paulo: Cortez, 2002. 
NOSELLA. Paolo. Compromisso Político e Competência Técnica: 20 anos depois Educ. Soc., Campinas, vol. 26, n. 90, p. 223-238, Jan./Abr. 2005223 Disponível em $<\mathrm{http}$ ://www.cedes.unicamp.br>. Acesso em 12/04/2009, $19 \mathrm{~h}$.

PALUDO, Conceição. Educação popular em busca de alternativas: uma leitura desde o campo democrático popular. Porto Alegre: Tomo Editorial, 2001.

SADER, Emir. Quando Novos Personagens entraram em cena - Experiências e lutas dos trabalhadores da Grande São Paulo. São Paulo: Paz e Terra, 2a edição. 1995.

SHIROMA, Eneida Oto e MORAES, Maria Célia Marcondes de. EVANGELISTA, Olinda. Política Educacional. $2^{\text {a }}$ ed. Rio de Janeiro: DP\&A, 2002.

SEVERINO. Antonio Joaquim. Educação, ideologia e contra ideologia. $1^{\mathrm{a}}$ ed. São Paulo: E P.V, 1986.

SOUZA, Dileto D. Organizações não Governamentais: Um estudo de caso da Federação de Órgãos para Assistência Social e Educacional (FASE), tese de doutorado UFRGS. Porto Alegre: 2005.

THOMPSON, E.P. Tradición, revuelta y consciencia de clase. Estudios sobre la crisis de la sociedad preindustrial. Barcelona: Crítica/Grijalbo, 1979.

WANDERLEY, Luiz Eduardo W. Educar para transformar: Educação popular, Igreja Católica e política no Movimento de Educação de Base. Petrópolis, Rio de Janeiro: Vozes, 1984.

WOOD, Ellen Meiksins. Democracia contra o Capitalismo. Tradução de Paulo Sérgio Castanheira. São Paulo. Boitempo, 2003.

Artigo recebido em: 16/5/2009

Aprovado para publicação em: 31/08/09

Revista HISTEDBR On-line, Campinas, n.34, p.154-166, jun.2009 - ISSN: 1676-2584 166 